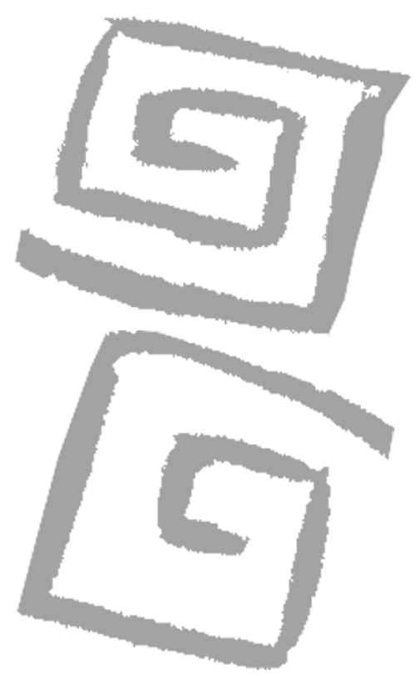

\title{
El proyecto político y las capacidades de gobierno
}

\section{The political project and governance capacities}

${ }^{1}$ Doctor en Salud Colectiva. Director del Instituto de Salud Colectiva, Universidad Nacional de Lanús, Argentina.

hugospinelli09@gmail.com

Spinelli, Hugo ${ }^{1}$

RESUMEN En este trabajo se realiza una revisión teórica sobre las capacidades de gobierno personales (experiencia, liderazgo y conocimiento) y las capacidades de gobierno institucionales (capital organizativo disponible) y su relación con lo político y las políticas en el contexto de América Latina. A partir de la producción teórica de Carlos Matus sobre la acción de gobernar, se ponen en discusión diversas dimensiones de esta problemática, las que se relacionan con otros autores y experiencias de diferentes momentos históricos. Se desarrollan teorías, métodos y técnicas de gobierno y se analiza la necesidad de la reforma del Estado desde una lógica interna. Se concluye en la necesidad de construir una teoría para la práctica de gobernar/gestionar las organizaciones públicas. Esa construcción requiere de acciones creativas que utilicen la teoría como caja de herramientas.

PALABRAS CLAVE Capacidad Organizacional; Capacidades de Gestión; Gobierno; Gestión; Políticas; Reforma del Estado.

ABSTRACT This article presents a theoretical overview of personal and institutional governance capacities (experience, leadership and knowledge on the individual level, and organizational capital available on the institutional level) and their relationship to politics and policies in the Latin American context. Using the theoretical production of Carlos Matus regarding the act of governing, diverse dimensions of this problem are put into discussion in relation to other authors and experiences in different historical moments. Theories, methods and techniques of government are explored and the need for state reform with an internal logic is analyzed. It is concluded that there is a need to build a theory for the practice of governing/managing public organizations, and this construction requires creative actions that use theory as a toolbox.

KEY WORDS Organizational Capacity; Management Capacity; Government; Management; Policy; State Reform. 


\section{INTRODUCCIÓN}

En el contexto de la crisis del petróleo de la década de 1970, surgen desarrollos teóricos que cuestionan el modelo de Estado de Bienestar y plantean el concepto de "mercado político", aludiendo así a lo que consideran una "sobrecarga del Estado", según la cual cuantos más servicios brinda un gobierno, más espera la población que siga proporcionándolos (1-2). Esas críticas van a confluir en el denominado "pluralismo de bienestar" (1). La contracara a esos planteos fue la teoría de "la crisis de legitimación" (3-5), que defendía la intervención del Estado y reconocía la necesidad de un mayor financiamiento de esas demandas por parte de los gobiernos (6).

A fines de 1980, el Consenso de Washington, siguiendo el concepto de sobrecarga del Estado, propone para América Latina la apertura unilateral de la economía, la libre circulación de los capitales, el achicamiento del Estado, la privatización de las empresas públicas, la desregulación, la búsqueda de inversión extranjera directa y el endeudamiento. La mano invisible del mercado sería el gran ordenador social para lo cual se necesitaba menos Estado y menos gobierno. Esas reformas traerían también la descentralización, que colocaba en agenda las necesidades de asumir responsabilidades de gestión a numerosas personas sin experiencia ni formación para las mismas.

En la primera década del siglo XXI, en varios países de América Latina se recuperó la intervención del Estado con la aparición de un neokeynesianismo que parecía imposible ante la hegemonía del monetarismo. Esto fue el fruto de la unión de intereses de países como Venezuela, Brasil, Argentina, Bolivia, Uruguay y Ecuador, a los que luego se sumaron otros y así se revirtió la lógica instalada desde el Consenso de Washington: se necesitaba más Estado y más gobierno. Pero más allá de los indiscutibles logros y avances alcanzados en estos países y en la región, no se pueden obviar las dificultades que tuvieron/tienen sus gobernantes para llevar adelante sus proyectos políticos: por un lado, enfrentan intereses muy importantes $y$, por otro, al asumir los cargos pueden encontrarse con bajas capacidades de gobierno institucionales (capital organizativo a disposición) y/o con bajas capacidades de gobierno personales (conocimiento + experiencia + liderazgo), las que pueden actuar de manera sinérgica o aislada (7).

\section{LO POLÍTICO, LA POLÍTICA Y EL GOBERNAR}

Chantal Mouffe señala la diferencia entre lo político y la política (8). Para esta politóloga belga, lo político -nivel ontológico, que refiere a la esencia- está relacionado por naturaleza al poder, al conflicto y al antagonismo; a diferencia de la política -nivel óntico, que refiere al ente, a lo empírico- relacionada con las prácticas e instituciones que formulan ciertos propósitos con los que buscan mantener o construir hegemonía. Lo político, para Mouffe, es sustancial para entender la dinámica de la historia y la construcción de la democracia, enfrentando así la visión de lo político surgida de los "enfoques racionalistas dominantes en las teorías democráticas" (8 p.16).

Los cambios ocurridos en América Latina en las últimas décadas coinciden con haber podido plantear lo político como eje conceptual de un momento histórico y, a partir de allí, diseñar políticas, que indefectiblemente exigen capacidades de gobierno -personales e institucionales- para ser llevadas a cabo. Es sobre estas relaciones que estructuramos este texto, destacando que lo político, desde nuestro punto de vista, tiene el mayor nivel de jerarquía.

En el siglo XIX, Saint-Simon afirmó la necesidad de pasar del gobierno de los hombres a la administración de las cosas (9). A fines de ese siglo, Porfirio Díaz, siete veces presidente de México, pregonaba "más administración y menos política". Esas ideas perduran en los planteos tecnocráticos que desprecian el valor de lo político y reducen todas las soluciones al mundo de la gerencia. En las antípodas, se ubican algunos ámbitos académicos y/o partidarios que jerarquizan lo político y desvalorizan la gestión. Se plantean así falsas opciones, ya que separar la política de las acciones de gobernar es instalar a la primera en una lógica del "debe ser", subestimando que gobernar/gestionar (a) es una de las formas 
de concreción de lo político, a través de las políticas, en un juego con múltiples actores que definen una lógica del "puede ser". Confundir el "debe ser" con el "puede ser" es una señal de mal cálculo político (10). Esto ya había sido identificado por el novelista ruso León Tolstoi (18281910) al afirmar que: "Es fácil escribir leyes, pero difícil gobernar" (12 p.468).

Los dilemas entre estos conceptos solo pueden ser sostenidos desde un alto nivel de ideologización que renuncie a pensar lo político, la política, el gobierno y la gestión como continuidades que se retroalimentan. Ninguna de ellas puede, de manera aislada, asegurar la concreción del proyecto político. De persistir en esos planteos, acumularemos capacidades críticas sin capacidades de transformación, autocondenándonos a ser meros opositores, sin posibilidades de transformar la realidad, haciendo de la profecía un culto. Poder conjugar actitud crítica con aptitud crítica resulta más que necesario (13).

Los cambios políticos ocurridos en América Latina han colocado a no pocos militantes ante la difícil y compleja tarea de gobernar/gestionar (b), y en esas experiencias es donde tienen que "aprender", a veces, de manera no muy saludable, que querer no es poder y que tampoco alcanza con ser honestos, tener buenas intenciones, ser inteligente, buen orador, carismático, tener experiencia política y/o un discurso correcto con el momento histórico para gobernar/gestionar. No se tardará en descubrir que no todo es imputable a la "pesada herencia" del gobierno o de la gestión anterior, sino que también la pobreza de las propias capacidades de gobierno conspira para poder superar aquella herencia a la que se le atribuyen todos los males. Esas carencias afectan el cumplimiento de las promesas electorales, dejando una frustración en los conjuntos sociales que se expresa en el "son todos iguales" con el consiguiente descrédito para lo político. La crisis de 2001 en Argentina y el actual movimiento de los indignados en la eurozona son claras evidencias de lo anterior.

En otras palabras, lo político expresa los conflictos de intereses producto de las diferentes posiciones de los actores en el espacio social, pero si en el juego democrático se gana una elección aparece otro desafío: el de gobernar/gestionar, que puede poner en evidencia las bajas capacidades para implementar las políticas que se formulen desde lo político (c). Esto ya no se relaciona con el conflicto de intereses sino que remite a otro conflicto: el cognitivo. ¿Por qué ubicamos las capacidades de gobierno como un conflicto cognitivo? Por la brecha existente entre la conciencia discursiva y la conciencia práctica (14).

Al pasar de oposición a gobierno, irrumpe en escena el temible "día después" y es en esa realidad donde se descubre que el capital político (15) no significa ni garantiza las capacidades de gobierno personales e institucionales, lo cual rara vez se problematiza antes de llegar a ocupar los cargos. En general, se presta más atención a lo político y es lógico que así sea por su importancia, pero esto no justifica ignorar la relevancia de las capacidades de gobierno.

Los tipos ideales que Weber desarrolla en El científico y el político (16) siguen teniendo vigencia en tanto descripción de rasgos dominantes, pero situar la discusión en esa dicotomía es un error, dado que significa ignorar las dimensiones tecnopolíticas de gobernar/gestionar.

Es necesario colocar en agenda las capacidades de gobierno de aquellos que vayan a ocuparse de ejecutar las políticas, independientemente de su nivel de instrucción y/o profesión, ya que en realidad el déficit es de todos: universitarios y no universitarios. Esas carencias deberían trabajarse con anterioridad a tener responsabilidades ejecutivas a través de "escuelas de gobierno" (10), no porque pensemos que en ellas van a aprender todo -ninguna de ellas superará la riqueza adquirida en la experiencia- pero al menos se podrán conocer algunas cuestiones y ejercitar otras, así como reflexionar con otros actores que hayan pasado por la experiencia de gobernar/gestionar, de manera de no llegar sin ningún tipo de preaviso ni conocimiento sobre las singularidades y complejidades que se van a enfrentar. Esas escuelas deberán ser espacios de formación de cuadros y no lugares de adoctrinamiento que nieguen lo reflexivo.

En América Latina, la producción bibliográfica acerca de gobernar es predominantemente descriptiva, ya sea sobre los gobiernos o sobre la implementación de las políticas públicas, siendo muy escasa la producción propositiva acerca de las capacidades de gobierno, sobre todo si no tenemos en cuenta las propuestas que se inscriben en las lógicas de las reformas del 
Estado impulsadas por el neoliberalismo. Una búsqueda en las dos principales bases de datos de publicaciones científicas de América Latina de acceso abierto, la Scientific Electronic Library Online (SciELO) y la Red de Revistas Científicas de América Latina y El Caribe (Redalyc), en función de términos seleccionados, arrojó los resultados que se visualizan en el Cuadro 1.

Los datos del Cuadro 1 reflejan la debilidad temática en las publicaciones científicas de América Latina acerca de las capacidades de gobierno, sobre todo en los aspectos que contemplan dimensiones del "qué hacer" y el "cómo hacer", que se expresan en los términos capacidades de gobierno, técnicas de gobierno y escuelas de gobierno. Por el contrario, encontramos un mayor número de publicaciones asociadas al "debe ser" que se asocian a los términos gobierno, políticas públicas y reforma del Estado. Las diferentes frecuencias encontradas avalan -a nuestro entender- lo que señalamos como el falso dilema entre política y gobernar. Una mención aparte merecen los términos de liderazgo y gobernanza que tuvieron amplia difusión en el marco de las reformas de segunda generación (d) impulsadas por los organismos multinacionales de crédito durante la década de 1990.

\section{TESTIMONIOS SOBRE LA ACCIÓN DE GOBERNAR}

En la historia se encuentran numerosos relatos que hacen referencia al déficit en las capacidades de gobierno y a la complejidad que se enfrenta en la acción de gobernar.

En el siglo XVI podemos referenciar a dos pensadores preocupados en la formación de los gobernantes, Nicolás Maquiavelo (1469-1527) y Erasmo de Rotterdam (1466-1536). Maquiavelo, en 1513, en el capítulo XXV de su obra El Príncipe (20), señala que la suerte puede gobernar la mitad de las acciones, pero al dejarnos gobernar la otra mitad tendremos que tomar el control de ello. Para él, el gobernante tiene como misión la felicidad de sus súbditos y esta solo puede conseguirse con un Estado fuerte. Y si para conseguirla es necesario recurrir a la astucia, al engaño o la crueldad, deberá hacerlo. Él considera que los
Cuadrol. Número de publicaciones en las bases de datos SciELO ( $n=367.441)$ y Redalyc $(n=228.397)$ según términos seleccionados. Mayo de 2012.

\begin{tabular}{lccc}
\hline Términos & SciElOa $^{\mathbf{a}}$ & Redalyc $^{\mathbf{b}}$ & Total \\
\hline Capacidades de Gobierno & 17 & 3 & 20 \\
Técnicas de Gobierno & 34 & 0 & 34 \\
Liderazgo & 397 & 324 & 721 \\
Escuela de Gobierno & 25 & 1 & 26 \\
Gobierno & 1.390 & 587 & 1.977 \\
Gobernanza & 115 & 129 & 244 \\
Políticas Públicas & 2.308 & 584 & 2.892 \\
Reforma del Estado & 191 & 78 & 269 \\
\hline
\end{tabular}

Fuente: elaboración propia a partir de SciELO y Redalyc.

a. Método de búsqueda integrada, base regional.

b. Método de búsqueda por palabra clave.

medios no importan, no es necesaria la moral, sino un realismo práctico, ya que considera a la política y a la moral como dos ámbitos distintos e incluso contradictorios (20). Esta obra es aún hoy referenciada en el mundo empresarial como forma de llevar adelante una organización. En 1516, Erasmo de Rotterdam publica La educación del Príncipe Cristiano dedicada a Carlos V, donde se preocupa por el sentido que debe tener la educación del príncipe, colocándose en las antípodas de Maquiavelo al insistir en la necesidad de educarlo sobre la base de ideas de paz y justicia (21).

En la segunda mitad del siglo XVIII, en Rusia, Catalina la Grande (1729-1796) le comenta a Diderot, figura relevante del iluminismo y su asesor en el imperio ruso:

...he oído con el mayor placer lo que vuestro brillante espíritu os ha inspirado; pero con esos grandes principios, a los que comprendo muy bien, se harán bellos libros y muy mala tarea. En vuestros planes de reforma olvidáis la diferencia entre nuestras respectivas posiciones: vos trabajáis sobre el papel, que todo lo soporta; es una materia unida, flexible, que no pone obstáculos a vuestra imaginación y vuestra pluma. En cambio yo, pobre emperatriz, trabajo sobre la piel humana, que es mucho más irritable y cosquillosa. (22 p.243) 
En 1758, en su libro Discurso sobre Economía Política, Jean Jacques Rousseau afirmaba: "La naturaleza ha creado multitud de buenos padres de familia, pero es dudoso que desde que el mundo existe, la sabiduría humana haya podido formar a diez hombres capaces de gobernar a sus semejantes" (23 p.15). En 1797, John Adams, segundo presidente de EE.UU., expresaba: "Mientras todas las demás ciencias progresaron, la de gobernar marcó el paso: hoy es practicada apenas un poco mejor que hace tres o cuatro milenios" (7 p.13).

En los primeros años de la década de 1980, Carlos Matus escribía en homenaje a Salvador Allende:

...créame señor presidente, que su heroísmo le ahorró el bochorno de ver correr apresurados hacia el lado opuesto de los ideales que confesaron a muchos que parecían ejemplares de lealtad, la confusión reemplazó al dogmatismo. Vivimos entre dos grandes confusiones que aisladas son costosas y juntas son nefastas, la primera, apunta a la crisis de las ideologías. La segunda a la pobreza de los métodos de gobierno. (24 p.12)

Después de la quiebra del Banco Ambrosiano, en 1982, el arzobispo Paul Marcinkus, máximo responsable de esa institución durante 18 años, afirmó: "no se puede gobernar la Iglesia con el Ave María" (25). No es el único ejemplo que podemos recuperar de hombres de esa institución. El pragmatismo del cardenal Richelieu (1585-1642) estaba muy lejos de la declamada piedad cristiana. Lo mismo podemos encontrar en quien lo sucedió en 1642, el cardenal Mazarin (1602-1661), que escribe el Breviario de los políticos, texto en el que reconoce la complejidad de la administración del Estado, como también indica que no se debe dudar en obtener poder por la pura manipulación del consenso si ello asegura el poder gobernarlo (26).

Las reflexiones sobre la complejidad de gobernar no son patrimonio del pasado, ni de los países del primer mundo. En el año 2010, al asumir como presidente de Uruguay, "Pepe" Mujica afirmaba:
Descubrimos que gobernar era bastante más difícil de lo que pensábamos, que los recursos fiscales son finitos y las demandas sociales infinitas, que la burocracia tiene vida propia, que la macroeconomía tiene reglas ingratas pero obligatorias. (27)

Ese mismo año, en un discurso durante la ceremonia de conmemoración de los 10 años del Foro Social Mundial en Porto Alegre, el por entonces presidente de Brasil, Luiz Inácio Lula da Silva, expresó: "Nosotros supimos después que Ilegamos al gobierno, que hay una diferencia fundamental entre lo que un gobernante soñó la vida entera y lo que un gobernante consiguió realizar en su gobierno" (28). Poco tiempo después, en el mismo año, la actual presidenta de Brasil, Dilma Rousseff, señalaba: "Ser presidente es como escalar el Everest todos los días" (29). La actual gobernadora de Tierra del Fuego, Fabiana Ríos, al inicio de su primer gobierno y en medio de una profunda crisis económica y política afirmó "dirigir la provincia es 'un verdadero parto, pero todos los días'" (30).

Estos relatos no solo se encuentran en los macro niveles de gobierno sino también en la gestión institucional del meso y micro gobierno, donde podemos escuchar: "la gestión es remar en dulce de leche repostero"; "nado, nado, y nada"; "me siento un bombero apagando incendios"; "me la paso tapando agujeros"; "al final de la tarde no me voy, ¡huyo!".

Las preguntas que caben entonces son: ¿por qué a veces los sueños se vuelven pesadillas, los gobiernos desgobiernos y la gestión indigestión?, ¿se trata solo de un problema de poder?, ¿cuánto tienen que ver en ello las capacidades de gobierno?, ¿hay además un conflicto cognitivo?

\section{LAS CAPACIDADES DE GOBIERNO Y EL CONFLICTO COGNITIVO}

Para entender la relación entre los dos conceptos que titulan este apartado es necesario abordar, para deconstruir, un modelo de conocimiento, es decir, una racionalidad hegemónica que impregna discursos y prácticas y que es propia de la modernidad. 
No es difícil constatar que las diferencias ideológicas entre los partidos políticos suelen ser mayores en los procesos electorales que durante los períodos en los que gobiernan $(10,24,31)$. ¿Por qué?, porque se enfrentan actores poderosos que no se tuvieron en cuenta en la promesa electoral (surgen los conflictos de intereses vinculados a "lo político"). Pero no todo se puede reducir al conflicto de intereses, hay también un conflicto cognitivo que, de manera independiente de las ideologías, reproduce una racionalidad que implica una lectura de lo social cosificada (relación sujeto-objeto, que niega al "otro"), en la que los problemas son entendidos como simples y las situaciones que se enfrentan como finales y cerradas, y donde el pensar se estructura a partir de soluciones y no de problemas. La raíz de ese pensamiento, expresado, por ejemplo, por la planificación normativa en la década de 1960 (32), tiene su base epistemológica en la concepción cartesiana del sujeto y en los desarrollos posteriores de Kant, para quien la razón le dicta las leyes a la naturaleza (33). Por lo tanto, la realidad no importa porque la construye el hombre, expresión clara de una matriz idealista que subyace aun en la enseñanza universitaria y que en la temática de gobernar/gestionar la reduce a la administración de los objetos en vez de entenderla como el gobierno "de" $y$ "con" las personas.

Así el gobernante tiende a pensar y actuar como si jugara solo y ubica al otro como mero espectador, desconociendo aquello que es evidente en un juego: jtodos juegan! Dante Panzeri, periodista deportivo, definió al fútbol en la década de 1960 como "dinámica de lo impensado" (34). Sin embargo, desde las universidades se continúa enseñando cómo hacer del juego de gobernar/gestionar -algo que es infinitamente más complejo que el fútbol- un proceso predecible y posible de planificar por la racionalidad técnica. Le llevará tiempo al gobernante entender que todos juegan (24), y cuando lo comprenda, no será raro que tenga la sensación de que juegan todos menos él. En síntesis, tanto técnicos como políticos, no saben que no saben y, en esas circularidades negativas, hacen lo que saben: si es un universitario desarrollará su experticia profesional y si es un político desarrollará sus experiencias de "la política" $(10,24)$.
Pero no solo los saberes especializados de los profesionales resultan insuficientes para gobernar, también es insuficiente la experiencia del político para abordar la mayoría de los problemas que se enfrentan durante la acción de gobernar. Y, no pocas veces, la incapacidad de llevar adelante las políticas se constituye en el principal obstáculo de un gobierno. No es casual que, en general, la gestión pública termine por ser desilusionante, de baja calidad y descentrada de los problemas de la gente, la ecuación resultados/esfuerzo sea pobre y, a su vez, se desconozca cómo mejorarla $(7,10)$.

Muchos dirigentes políticos siguen pensando que lo fácil es gobernar y lo difícil es ganar una elección, lo cual puede ser verdadero, o no, de acuerdo al fin que se persiga. Tampoco es algo que se resuelva con la eliminación de los partidos, ni con la extrapolación de técnicas de gerencia de las escuelas de negocios, o convocando a personas del mundo empresarial, como algunos creen y postulan en clara ignorancia de la especificidad de la gestión pública, ni tampoco con la lectura de algunos de los bestseller sobre el tema que se encuentran en las librerías $(7,35)$.

La política sin ciencia es religión (24) pero también la ciencia necesita de política $(36,37)$, ya que los problemas no son ni técnicos, ni políticos, sino tecnopolíticos (24). Avanzar en esta dirección evitará seguir confundiendo capacidad de gobierno con un Master of Business Administration (barbarismo técnico); o caer en el barbarismo político de confundir capacidades de gobierno con "rosca"; proyecto de gobierno con "verso" y gobernabilidad con "poroteo" (e). Todas lógicas que forman parte del lenguaje corriente del capital simbólico del campo de la política (15).

Matus entiende que el gobernar/gestionar es procesar problemas a los que define como la diferencia percibida por un actor-individual o colectivo- entre la situación observada y la deseada, situación a la que ese mismo actor señala como un resultado adverso, insatisfactorio y evitable desde sus intereses (31). Una situación, si no se puede problematizar, se dirá que está naturalizada y por lo tanto será funcional al statu quo. La lógica de causalidad lineal instaló la idea de soluciones, muy apropiada para problemas simples (todas las variables y las relaciones entre ellas son conocidas) pero infrecuente, ya que cuando se 
gobierna se enfrentan sobre todo problemas complejos (la mayoría de las variables y sus relaciones son desconocidas y pueden mutar en el tiempo). Los problemas constituyen el primus movens y la "materia prima", de allí que el gobernante o gestor que se queje por la existencia de estos, demostrará que no entendió el sentido y la dinámica de "este juego". Claro que hay que tener ciertas precauciones, por ejemplo, si los problemas son siempre los mismos, se deberá pensar si no están faltando "normas" sobre ciertos procedimientos. Por el contrario, si los problemas cambian continuamente, se deberá analizar la probabilidad de que se esté trabajando en un contexto muy inestable y entonces pensar en "normas" para resolverlos será un error que seguramente se pagará muy caro. Ahora, si cada día que pasa se enfrentan problemas nuevos de mayor magnitud, es muy probable que se esté extendiendo el espacio situacional y que, por lo tanto, sean mayores las probabilidades de tener que enfrentar actores más poderosos, por lo que la viabilidad del proyecto podría comenzar a fragilizarse, lo que obligará a tomar recaudos (construir poder, obtener mayor legitimidad y/o realizar alianzas). Esas acciones no significan retroceder, es necesario pensar que la continuidad puede no ser lineal, sino contradictoria y que por lo tanto habrá que saber resolver el dilema "fuerza vs. consistencia", en el que un aumento de la fuerza acarreará algún grado de pérdida de consistencia y viceversa (38); dilema necesario de asumir si se pretende construir hegemonía.

Si los problemas son el eje de la acción de gobernar/gestionar se deberá pensar una forma de trabajar con ellos para resolverlos y no para inmolarse en el intento. Parafraseando al general George Patton podríamos decir: "el objetivo de la guerra no es morir por la patria de uno, sino conseguir que el enemigo muera por la patria de él" (39 p.13). Con esta frase buscamos evitar la lógica quijotesca, tan propia de los hispanos, de ir contra los molinos de viento (40). En síntesis, lo que se procura es omitir cualquier vocación de mártir para reemplazarla por un pensar/actuar relacional.

La sensación del gobernante o el gestor sobre su trabajo es que es infinito, ya que a diferencia del trabajo manual es muy difícil que al final del día se tenga la sensación de haberlo terminado, siempre quedan cuestiones pendientes por resolver. Se deberá entender que se trabaja con redes de problemas interrelacionados cuasi imposibles de aislar, denominadas por Russell Ackoff como "malla de sistemas de problemas" (41 p.36). Esto no es producto de ninguna intervención sobrenatural, ni la encarnación del mito de Sísifo ( $\mathrm{f}$ ), sino que responde a las características de trabajar con problemas complejos, de naturaleza social, que resultan del juego de intereses de actores/agentes (g). Los problemas complejos se caracterizan por el hecho de que su abordaje siempre determina una nueva situación de mayor o menor complejidad, es decir que sus resoluciones son situacionales, buenas para unos, malas para otros. Todo ello hace que sea muy raro que los problemas complejos desaparezcan, en general se consigue un intercambio de problemas donde siempre habrá una nueva situación más o menos compleja que la anterior.

Poder superar el conflicto cognitivo implica reconocer que el gobernar se enmarca en procesos relacionales -interacciones sujeto-sujeto- y como todo proceso relacional tiene en sí la potencialidad de la creación y/o del conflicto, así como también la relevancia de las dimensiones simbólicas en sus acciones (lenguajes verbales y no verbales). En síntesis, todo lo real es relacional y por lo tanto no hay espacio para el principio de sustancialidad ligado al sentido común que trata las actividades de personas y/o grupos como propiedades sustanciales, inscritas de una vez y para siempre, desconociendo los conceptos de "espacio social" y "trayectorias" desarrollados por Pierre Bourdieu (43).

Ese conflicto cognitivo descansa en una matriz que incluye lo real y lo imaginario pero desconoce o minimiza el valor de lo simbólico (44). Así, el sujeto es visualizado como un ente cartesiano, donde el mismo gobernante se ve a sí mismo como tal e imagina así a sus equipos (7). Se desconoce la circularidad negativa que configuran cinco falsos supuestos (45):

- El supuesto de que el sujeto es el de la razón pura descripto por Descartes y, por lo tanto, se ignora que es un sujeto barrado que desconoce una parte de sí mismo (sujeto del inconsciente), omitiendo los desarrollos que conceptualizan al sujeto como un sujeto complejo, capaz de pensar pero también de amar, odiar, 
Ilorar, deprimirse o ser indiferente (46). Y aun en ese estado de conciencia del sujeto cartesiano que asociamos al homo sapiens, debemos asumir -como indica Sartre- que no solo somos sapientes sino sabidos (47).

- El supuesto de que las organizaciones son pirámides, desconociendo, por ejemplo, desarrollos teóricos como los de la "Teoría de las Macroorganizaciones" (35) y de la "Burocracia Profesional" (48).

- El supuesto de que el trabajador es solo un trabajador manual cuando en muchos casos lo central de sus procesos de trabajo es lo simbólico (lenguaje verbal y no verbal).

- El supuesto de que el trabajo del gobernante o el gestor es planificar y que por lo tanto su trabajo es ordenado, enfocado y lineal, ignorando que su labor cotidiana implica un manejo de situaciones caóticas, imprevisibles y desordenadas (49).

- El supuesto de que se producen bienes (lógica de producción, circulación y consumo) cuando la mayoría de las veces se producen servicios (se producen cuando se consumen) (50).

La práctica del gobernante puede ser asociada a lo que Bourdieu denomina "conocimiento sin conceptos" (43). No es muy distinto lo que ocure a nivel gerencial en el mundo empresarial. Mintzberg señala que los gerentes no hacen lo que les gusta pensar que están haciendo (49). En su tesis de doctorado The nature of managerial work -realizada en los primeros años de la década de 1970describe al gerente como un esclavo del momento, yendo de tarea en tarea presionado por necesidades urgentes y cotidianas, todas muy lejos de la idea de dedicar el tiempo a preparar acciones de largo plazo. Así, el tiempo medio que gasta en un asunto específico no es superior a los nueve minutos. Mintzberg describió las características del trabajo de un gestor (recordemos que está hablando del mundo industrial y comercial y no de lo público) de la siguiente manera (49):

- Ejecuta una gran cantidad de tareas en un ritmo alucinado.

- Se empeña en actividades caracterizadas por lo breve, lo variado y lo fragmentado.

- Tiene preferencia por asuntos que sean actuales, específicos y no rutinarios.
- Prefiere el medio de comunicación verbal al escrito.

- Actúa en el ámbito de una red de contactos internos y externos.

- Está sujeto a enormes limitaciones pero consigue ejercer algún control sobre las tareas.

Esas regularidades de las prácticas de gobernantes/gestores señala un modelo de conocimiento (racionalidad), que tiene su historia y se relaciona con cuestiones estructurales (económicas, políticas, ideológicas y culturales), por lo que no limitamos la caracterización a un sector ideológico o a lo público, ya que la descripción expresa la complicidad ontológica entre el campo y el habitus $(15,42)$.

\section{LAS CAPACIDADES DE GOBIERNO PERSONALES}

Los griegos planteaban la importancia de la capacidad de un gobernante para gobernarse a sí mismo (moral) y para gobernar su familia (economía). Esas ideas son retomadas por Michel Foucault, quien describe la formalización del Estado gubernamentalizado (a partir del siglo XVIII). En su análisis incluye las artes de gobernar, que comprenden el estudio del gobierno de sí (la ética, como forma de dominar los placeres y los deseos), el gobierno de los otros (las formas políticas de la gobernabilidad) y las relaciones entre el gobierno de sí y el gobierno de los otros, relaciones que conjugan experiencias con saberes (51-53).

La experiencia en el gobierno de Salvador Allende, entre 1971 y 1973, le permitió a Carlos Matus entender que habían subestimado la complejidad de la acción de gobernar/gestionar en los desarrollos previos de la planificación (24). Al salir en libertad, luego de tres años en la cárcel de la dictadura pinochetista, su rol de consultor de Naciones Unidas y luego de la fundación Altadir (Alta Dirección), de la cual era presidente, le permitió asesorar a gobiernos de distintas identidades políticas, a niveles nacionales, provinciales y/o municipales, en distintos países de América Latina. En esos años volvió a constatar cómo las débiles capacidades de gobierno eran una limitación para cumplir con la promesa política. 
Así, grandes capacidades de gobierno personales con bajas capacidades de gobierno institucionales -o viceversa- terminaban en pobres resultados con relación al proyecto político. Podemos rescatar tres afirmaciones de Matus en ese sentido: "ningún gobierno puede ser mejor que su selección de problemas" (10 p.432); "un gobierno no puede ser mejor que la organización que comanda" (24 p.327); y "la oficina del gobernante impone un techo de calidad de toda la gestión pública" (7 p.163).

Matus señala tres dimensiones en las capacidades personales de gobierno: la experiencia, el liderazgo y el conocimiento (7), las que describiremos, profundizando en la última.

\section{La experiencia}

Es un componente muy importante dentro de las capacidades de gobierno personales. Tiene la particularidad que solo se adquiere en la práctica, no se puede enseñar. Habrá que pasar por diferentes situaciones para adquirirla y aun así el aprendizaje nunca será total, ya que el momento histórico, la combinación de los intereses de los actores, las características de los problemas, de los equipos y del propio gestor harán que cada situación que se aborde sea muchas veces única $y$, por lo tanto, imposible de ser reducida a una norma. En síntesis, esta dimensión de las capacidades de gobierno se basa en una lógica de ensayo-error y de errorensayo que expresa lo subjetivo y lo situacional $y$, por lo tanto, la imposibilidad de su total objetivación, lo cual señala los límites de la academia para la formación de gobernantes, al menos en este aspecto.

La relevancia de la experiencia en la dirección de las organizaciones, lleva a Mintzberg a discutir los límites de los Master of Business Administration (MBA):

La idea de aceptar personas de 25 años -inteligentes, pero inexpertas- sin la menor práctica en gerencia, para tornarlas dirigentes eficientes en dos años de entrenamiento en las aulas es irrisorio [...] Ya es tiempo de acabar con los cursos tradicionales de maestría. Deberíamos estar desarrollando gerentes de verdad, no fingiendo que ellos pueden ser creados en las aulas de las universidades. (54 p.164-165)

También Russell Ackoff señala los límites de la enseñanza académica de estos temas al afirmar: "Las escuelas de administración alcanzan resultados mucho mejores en la educación de sus profesores que en la de sus estudiantes" (41 p.177). Estas críticas se sustentan en la convicción de que es la práctica diaria -y no la universidad- la que enseña en este tema, lo cual no quita la necesidad y posibilidad de reflexionar sobre esta y es allí donde las universidades, si saben hacerlo, pueden colaborar con la formación de gobernantes y gestores. Pero para ello es necesario revertir la conformación decreciente en los currículos de los contenidos de información, conocimiento y comprensión (41 p.171); estructura curricular que expresa una visión iluminista y muy poco constructivista de la práctica de gobernar/gestionar.

La falta de experiencia suele acarrear para el gobernante distintos adjetivos: el de soberbio, cuando actúa desoyendo los consejos institucionales, o el de inútil, cuando no consigue hacer andar la máquina de gobierno. Esos adjetivos calificativos, a veces pertinentes y otras no, suelen también remitir a la lucha entre lo instituido y lo instituyente, donde la experiencia actúa en general del lado de lo instituido (55). También se debe evitar que la anecdotización sea la única forma de capitalización de la experiencia y, para ello, habrá que luchar contra la inercia de una lógica de conocimientos sin conceptos, propia del gobernante que acumula experiencia pero no puede salir de la anécdota porque no logra conceptualizarla.

\section{El liderazgo}

El tema del liderazgo se relacionó, desde sus orígenes, con la idea de un "don" que remitía a algo divino y, por lo tanto, algunas personas lo tendrían y otras no. La concepción de liderazgo ha cambiado, dejó ya de ser percibido como un don, para ser considerado algo a trabajar en los equipos y posible de ser adquirido. Se busca así que dicho rol no quede limitado a una sola persona, sino que sea una potencialidad de 
la mayor parte de los integrantes del equipo que permita instalar un liderazgo grupal -preferimos Ilamarlo identidad grupal- por encima de cualquier liderazgo individual. Es decir, no planteamos el adoctrinamiento de muchos a la espera de alguien con el "don de liderazgo" para que los conduzca. Estas ideas jerarquizan la afirmación de Gastón Bachelard (1884-1962) quien en su trabajo El nuevo espíritu científico afirma: "No es el ser el que ilustra la relación, es la relación la que ilumina el ser" (56 p.162).

Los desarrollos teóricos acerca del lenguaje y la comunicación han realizado aportes significativos para el ejercicio del liderazgo. Una expresión de esto son las "técnicas de coaching" que, como toda moda, tienen ofertas de todo tipo: desde situaciones innovadoras, hasta viejas ideas en nuevos ropajes. Se trata de diferenciar la figura del jefe tradicional de esta nueva forma de liderazgo y, para ello, se concibe al lenguaje desde una visión no contable, por lo que deja de dar cuenta de lo existente, pierde su carácter pasivo y descriptivo para ser considerado como acción y como generador de nuevas realidades, identidades, relaciones y compromisos. Esto lleva a cuestionar principios clásicos del líder como: su posición de certeza y verdad absoluta; hablar en vez de escuchar; aseverar en vez de preguntar; definir funciones en vez de delegar responsabilidades; controlar en vez de motivar y comprometer; tener una autoridad otorgada en vez de tener una autoridad reconocida y mantener distancia en vez de construir vínculos.

En síntesis, si bien reconocemos una dosis de "arte" en el liderazgo, no hay arte que no tenga teoría por detrás y por ende su conocimiento mejorará el desempeño y la creación de nuevas formas de liderazgo.

\section{El conocimiento}

Como ya señalamos, Michel Foucault ubica en el siglo XVIII el pasaje del gobernar considerado como arte, al gobernar dominado por las técnicas de gobierno que toman como objeto a las poblaciones, momento en que surge la economía política (52). A pesar de los siglos, esas técnicas siguen siendo débiles, diría Matus, quien no buscaba el control de las poblaciones sino el modo de lograr poner al Estado al servicio de las mayorías, de allí su empeño en desarrollar teorías, métodos y técnicas de gobierno $(7,10,24,32,35,37,38,57)$.

El "triángulo de gobierno" $(7,10)$, una de las construcciones teóricas de Matus, está representado por un triángulo equilátero en su forma ideal, en el que uno de sus vértices está constituido por las capacidades de gobierno; otro, por el proyecto de gobierno, estructurado a partir de los problemas que se pretende abordar y que forman parte de la promesa política -es decir, debería contener lo político de manera explícita o implícita-; y el tercero, conformado por la gobernabilidad, representa el consenso que tiene el proyecto en los conjuntos sociales. No es frecuente encontrar este triángulo equilátero. ¿Por qué? Porque, en general, se tiende a pensar solo el proyecto político olvidando las capacidades y la gobernabilidad, o solo se piensa en las capacidades técnicas y se conforman tecnoburocracias estériles, o se diseñan modelos que descansan en un alto consenso en los conjuntos sociales que carecen de un proyecto político y de capacidades para resolver y/o abordar los problemas que se enfrentan. Las relaciones entre el proyecto y la gobernabilidad exigen diferentes capacidades de gobierno.

El gobernante y el gestor tienen que reforzar -o adquirir- sus capacidades de gobierno pero, en general, desprecian ese aprendizaje porque creen que Ilamando a especialistas podrán subsanar el déficit. No comprenden que si desconocen sus capacidades no solo no podrán usarlas sino que tampoco podrán exigirlas. Y es así que organizan capacitaciones para sus trabajadores, para sus equipos, pero no para sí. “¡Están demasiado ocupados!”, “¡no tienen tiempo para perder!". Mucha capacitación y pocos cambios será el balance que obtendrán. No es infrecuente que los integrantes de los espacios de capacitación le señalen al docente del curso: “¿no sería bueno que el que lo contrató escuchara lo que usted dice?", o "mire que las autoridades hacen todo lo contrario a lo que usted nos explica". El político piensa que con la experiencia le alcanza, que "sus años, la calle y las canas" son suficientes para gobernar/gestionar, y que esos tres factores son superiores a lo que se 
puede aprender en la universidad o de sus egresados. A veces no le falta razón, ya que los planteos tecnocráticos originados en las universidades pretenden hacer predecible lo impredecible, anulando el juego por una norma o un algoritmo. El recurso escaso será encontrar gobernantes con conocimiento + capacidad de liderazgo + experiencia. Por el contrario, lo más común será encontrar: conocimiento + experiencia, sin capacidad de liderazgo y entonces tendremos un asesor; o experiencia + capacidades de liderazgo, sin conocimiento y entonces tendremos un cabecilla, como afirma Matus (7).

¿Pero entonces qué hacer? Se puede y se debe trabajar con el gobernante, el gestor y sus equipos en las capacidades de gobierno y discutir teorías, métodos y técnicas. ¿Cuáles? Veamos algunas de ellas, empezando por las tres que constituyen el "triángulo de hierro del juego organizativo de la gestión": la "agenda del dirigente"; el "sistema de petición y rendición de cuentas" y la "gerencia por operaciones" (10), a las que sumaremos otras también del propio Matus y de otros autores. Este listado no pretende ser exhaustivo o traer fórmulas sino, a lo sumo, formas.

\section{La agenda del dirigente}

El tiempo y la comunicación no tardarán en instalarse como las dos grandes dificultades cotidianas (h): el tiempo, como un recurso insuficiente, y la comunicación, como una acción compleja y muchas veces indescifrable. Esto es una constante que se irá potenciando si no se trabaja y se le dedica atención. Pero, en general, esto no ocurre. ¿Por qué?, porque se cree que son recursos que no influyen en la acción de gobierno y que, además, se pueden planificar. Se niega que el tiempo es un recurso rígido, limitado e irreversible, del mismo modo que se piensa que la comunicación es solo un problema de transmisión, siguiendo los caducos paradigmas que postulaban la secuencia emisor, mensaje y receptor (58). En general, se ignoran las discusiones teóricas que se han desarrollado sobre el lenguaje y la comunicación $y$, por ende, la centralidad que tienen tanto en el "hacer" como en la "construcción de realidades sociales" (59-65).
La agenda del dirigente tiene como función permitir la administración del tiempo y mantener el foco de atención en el proyecto político. Pero, en general, la agenda parece armada por el enemigo, donde lo urgente desplaza a lo importante. Las reuniones se suceden sin cesar, sin orden ni procesamiento. El directivo mantiene reuniones y atiende llamadas que ocupan su ya escaso tiempo, sin entender por qué debe hacerlo. Es más, tiene la clara percepción de que muchas de esas acciones podrían haber sido mejor resueltas en otros ámbitos. A pesar de lo anterior, no analiza con periodicidad la agenda junto a su equipo. ¡No hay tiempo para ahorrar tiempo! Todos quieren verlo, su narcisismo da rápido paso a la preocupación, pero ya suele ser tarde. Está encerrado en esa lógica, asediado por grupos corporativos $y$ actores constituidos, lejos de aquellos que despertaron su preocupación y lo motivaron a que aceptara el lugar donde está. El "afuera" le impone temas, reuniones y eventos, "le marcan la cancha", se dirá en términos corrientes.

No hay tiempo de agenda reservado para el tratamiento de temas estratégicos, ni para su formación ni la de su equipo, lo que va a redundar en la incapacidad para poner el aparato burocrático al servicio del proyecto político (7). No hay valorización de audiencias, correspondencia, correos electrónicos, Ilamadas telefónicas, reuniones interinstitucionales, ni actividades protocolares. Todo parece pensado para un día de infinitas horas. El "menú diario de decisiones", en tanto producto de la agenda del dirigente, surge más como un resultado de la improvisación que de la planificación (7). No hay selección ni procesamiento previo de problemas, solo un uso indiscriminado del tiempo.

El dirigente no puede escapar a la confección de una agenda. Esta debe organizar su trabajo, actuar como un filtro para los asuntos banales que buscan acaparar su atención, postergando y confundiéndose con los problemas más importantes. Para lo cual debe entender que, para hacer un uso útil del tiempo, es más importante el control cualitativo que el cuantitativo, que depende del tipo de problemas que ingresan a la agenda tanto en jerarquía como en calidad (7). No es lo mismo dedicar tiempo a problemas sin análisis que pueden estar en un 
estadio de malestar, que abordar problemas con procesamiento previo tecno-político. Los problemas en estadio de malestar son de difícil comprensión y ataque, porque son confusos y superficialmente explicados; en general, suelen ser muy antiguos y están naturalizados, ignorando que son el resultado de un proceso de adaptación cultural a sus efectos negativos y de resignación social ante sus consecuencias $(7,10)$.

La racionalización de la agenda del dirigente es un estímulo para la descentralización de problemas no clasificados como de alto valor para esa agenda. La aspiración es la construcción de una agenda estratégica, capaz de administrar el tiempo del gobernante y mantener el foco en las prioridades del proyecto, con una estructura que permita la reserva de bloques horarios para el tratamiento de temas estratégicos, ubicando tareas de rutina, como firma de expedientes y audiencias en horarios prefijados.

\section{El sistema de petición y rendición de cuentas}

Existe un consenso cuasi generalizado acerca de la baja responsabilidad imperante en las organizaciones públicas, expresada en que nadie pide cuentas y nadie rinde cuentas. Esa situación exacerba una política en minúsculas ligada a las rencillas, los pequeños honores y al juego de los entornos, en detrimento de la política con mayúsculas, enfocada en los problemas de la gente. La ausencia de un sistema de petición y rendición de cuentas debilita a cualquier organización ya que su implementación es sustancial para mejorar la calidad de los procesos laborales/relacionales $(7,24)$. Debemos aclarar que no nos estamos refiriendo al mecanismo formulado por Frederick Taylor a inicios del siglo $\mathrm{XX}$, en el que solo los jefes pedían cuentas. Tampoco debe ser confundido con un sistema de premios y castigos. A lo que hacemos referencia es a un sistema multidimensional, donde todos piden cuentas y todos rinden cuentas, independientemente de posiciones y/o jerarquías, y ligado a los "proyectos de trabajo" individuales, grupales e institucionales, construidos de manera ascendente y discutidos en reuniones de trabajo por los mismos equipos.

\section{La gerencia por operaciones}

El gobernante o el gestor deben fomentar que los problemas se resuelvan donde mayor jerarquía tienen, ya que así serán tratados con la celeridad e interés que necesitan, características que se pierden al emigrar hacia estratos superiores donde ya no serán tratados como tales, sino que se transformarán en meros trámites. Si se aprende a delegar y se hace de ello un eje central de la acción, se obtendrá agilidad en el abordaje de los problemas y se ganará tiempo, que podrá invertirse en caminar la organización y el territorio, para intervenir en las conversaciones y mejorar la comunicación.

El organigrama es la manera tradicional de pensar e intentar hacer funcionar a las organizaciones, al que se suman las misiones y funciones (aunque con el grado de cumplimiento que tienen mejor sería llamarlas "usos y costumbres"). Estos conceptos constituyen la prehistoria de la teoría de la administración, pero ello no significa que no sigan teniendo fieles adeptos, ni que se hayan dejado de enseñar ya que vuelven aggiornados en las técnicas del management. De su inutilidad, da cuenta Russell Ackoff (19192009), un referente en la gerencia del pensamiento sistémico quien afirma: "los trabajadores británicos descubrieron un procedimiento muy efectivo para hacer que las organizaciones que los empleaban no funcionaran bien: trabajar como lo indica el reglamento" (41 p.121).

La gerencia por operaciones es central para delegar la resolución de problemas en los integrantes de los equipos. La idea consiste en generar "adhocracias", es decir, diseños organizacionales ad hoc, que desaparecen una vez cumplidos los objetivos de la operación (66). Delegar la responsabilidad en personas que en general no la tienen, o la tienen, pero no a esos niveles de decisión, persigue como propósito que los trabajadores sientan en esa designación un reconocimiento personal, que vivencien la complejidad de comandar un proyecto y que tengan la oportunidad de ser creativos y abandonar las rutinas. La gerencia por operaciones está ligada a la existencia de un sistema de petición y rendición de cuentas; la articulación de ambas es necesaria para aumentar la calidad de gobernar. 


\section{La oficina del gobernante}

Es muy raro que se piense su diseño, a pesar de ser el ámbito donde se desarrolla el proceso de toma de decisiones (7). Su concepción es, en general, más que precaria. Esta afirmación no se circunscribe al espacio físico, sino que va más allá, ya que alcanza a todos los espacios formales e informales en los cuales el gobernante, el gestor y su equipo procesan las decisiones que hacen a la direccionalidad de gobernar/gestionar (24). Parece un tema superfluo, pero basta ver y/o analizar el proceso de trabajo para entender su necesidad. En general, el cotidiano de la oficina del gobernante (OG) está marcado por papeles que no se encuentran y teléfonos que suenan sin cesar para conversaciones que podrían haberse resuelto en otra oficina. La disposición física del mobiliario también atenta contra su calidad, ya que sigue criterios más estéticos que funcionales (cercanía de lo innecesario y lejanía de lo necesario, sean áreas y/o personas). Los procedimientos tampoco ayudan: todo tiene que tener la firma de la máxima autoridad, quien desconoce en un muy alto porcentaje lo que firma, pero si quiere averiguarlo o revisarlo se encienden alarmas de que se detiene el proceso administrativo, lo que traerá serios problemas, por lo que deberá optar por callarse y seguir firmando, o enfrentar las profecías. Si sigue firmando, deberá hacerlo rápido, en la solapa de cada hoja que su secretaria/o le irá mostrando para no perder tiempo, ya que hay mucho por firmar.

El desorden lo llevará a anunciar hechos que aún están en discusión pensando que están cerrados, a firmar lo que no tenía que firmar, a prometer aquello que no puede y que nunca podrá concretar. Si esto resulta conocido, se podrá entender de lo que estamos hablando.

El gobernante necesita conformar en su oficina tres tipos de soporte: el técnico, el técnico-político y el cálido -con las personas más cercanas, familiares y amigos- (7). También es esencial establecer "filtros de calidad" que brinden procesamientos tecnopolíticos a los problemas antes de que ingresen a la agenda del dirigente, "filtros de valor" que permitan que los problemas tratados sean los pertinentes a su espacio situacional y "filtros a la entrada de problemas" que colaboren en la administración del tiempo (7). Un buen diseño de la OG permitirá eliminar o acotar las diferentes situaciones que se enfrentan y que obstaculizan el uso estratégico del tiempo (10). La OG conforma una trama con la agenda del dirigente, de allí la necesidad de trabajarlas en conjunto.

\section{Un sistema de información para la toma de decisiones}

Para graficar la situación del gobernante en relación con la disponibilidad de información necesaria para la toma de decisiones, podríamos imaginarnos al conductor de un vehículo a muy alta velocidad con el parabrisas pintado de negro y sin ninguna indicación de los parámetros más básicos de la situación del entorno, ni del vehículo. No sabe dónde está, a qué velocidad va, cuánta nafta le queda; desconoce la temperatura y la presión del aceite; si enfrente le espera un camino recto o sinuoso, de ripio o de asfalto o si tiene un paredón. ¡Ni hablar de tener un GPS! Eso sí, tiene dos espejos retrovisores con los que puede observar y contar todo lo que va atropellando en su andar. ¡Ahora sí puede ver lo que no pudo ver antes!, pero ya es tarde.

No se puede conducir a ciegas, sin datos ni información. El gobernante y el gestor necesitan información para la toma de decisiones, la cual debe ser ágil, de rápida lectura y presentada en formatos amigables. Tiene que permitirle supervisar y monitorear distintos procesos para conocer lo importante y lo necesario, no lo superficial e innecesario. Por ejemplo, los anuarios estadísticos pueden alimentar la "sala de situación" del gobernante, pero no resultar prácticos para él, que necesita un tablero de control ad hoc para lo que quiere monitorear. Esos tableros tendrán pocos indicadores pero lo suficientemente sólidos como para mantener cualquier discusión y/o tomar decisiones fundadas.

Los adelantos de las tecnologías de la información y la comunicación (TIC) suelen ser de gran ayuda ya que pueden colaborar en ahorrar tiempo y ganar eficiencia, en la medida que se incorporen efectivamente a los procesos de trabajo y a la toma de decisiones. Pero no podrán solucionar per se el tema, dadas las dimensiones subjetivas en juego de los que se comunican y/o actúan como generadores de datos, o que los cargan y/o los utilizan. El tema de los sistemas de 
información, las TIC, los sistemas de monitoreo y evaluación y los tableros de control pueden ser parte de las dificultades o soluciones para el gobernante, dependiendo de su existencia, de su utilización y de su calidad $(67,68)$.

\section{Coeficiente de transversalidad}

Lo vertical o lo horizontal, como formas de llevar adelante la gestión, está siempre en discusión y representa una manera de pensar sincrónica que desconoce la dinámica de los escenarios y actores con los que interactúa el gobernante a diario. Para romper esa situación, René Loureau, a partir de conceptos de Félix Guattari, postuló el "coeficiente de transversalidad" como forma de ruptura del antagonismo vertical vs horizontal, situaciones que prácticamente nunca se hallan en forma pura en la realidad. Este concepto nos permite pensar en lógicas más o menos verticales, o más o menos horizontales, como productos de las tensiones del juego y del contexto en una situación y un momento dado, en clara concepción diacrónica (55).

\section{Teoría de las macroorganizaciones y de las organizaciones}

La teoría de las organizaciones se pensó para el mundo industrial y hubo en ella escaso espacio para pensar las organizaciones sociales. Así, el conocimiento se estructuró en buena medida como una metáfora de la industria: la máquina, como símbolo de la racionalidad, aparece como la meta. Esas ideas conviven en las organizaciones sociales con la sensación en muchos trabajadores de un orden cotidiano que surge más del producto de la espontaneidad que de la racionalidad (69).

El gobernante ingresa al juego ignorando cómo es el campo de juego, o mejor dicho, lo imagina como una pirámide y se autoasigna el rol del faraón. Pero el campo de juego no es eso. Los diseños organizacionales en los que tendrá que "jugar" están muy alejados de las concepciones piramidales en las que se socializó. El diseño organizacional de los momentos fundacionales de la industria se le presentan obsoletos y las herramientas tradicionales de la jerarquía administrativa no le resultan eficaces (70). Vive criticando a la burocracia pero, cuando explicita sus ideales de organización, recita cuasi de memoria aquello que Weber describió como el ideal de la burocracia (71 p.173-174). La teoría de las macroorganizaciones (7) y de la burocracia profesional (48), por citar algunos de los diseños organizacionales que se configuran sobre la base de una lógica de juegos con múltiples jugadores, son en general ignoradas, y el tiempo que le lleve descubrirlas tendrá un alto costo.

\section{Técnicas de resolución de conflictos}

Se trabaja en organizaciones que cuentan con centenares, cuando no miles, de trabajadores, en las que se establecen infinitos procesos relacionales entre ellos mismos, con sus superiores y/o con los usuarios y, por lo tanto, los conflictos -como ya señalamos- son una posibilidad real, sean de intereses o cognitivos, y muy probablemente terminen siendo procesados emocionalmente si no se dispone de técnicas de resolución de conflictos. Sin embargo, es raro encontrar que esos mismos trabajadores hayan recibido capacitaciones en estos temas. No pretendemos suprimir los conflictos, sino que los integrantes de una organización decidan libremente en cada caso si utilizan la guerra, la persuasión, la mediación, la negociación, la imposición u otro medio estratégico que consideren oportuno. A lo que nos oponemos es a que los trabajadores utilicen siempre la guerra por ser la única técnica de resolución de conflictos que conocen. Pareciera que aún se siguen los dictados de Maquiavelo: "Un príncipe, pues, no debe tener otro objeto, ni otra preocupación, ni considerar competencia suya cosa alguna, excepto la guerra y su organización y dirección, porque este es un arte que corresponde exclusivamente a quien manda" (20 p.80). En síntesis, si la realidad es relacional y no sustancial (43), las capacidades de negociación son fundamentales, lo cual no significa que todo deba negociarse.

\section{La sala de situación}

Es un lugar muy próximo a la oficina del gobernante $(7,24)$, una unidad de procesamiento tecnopolítico en la que deben confluir tecnologías de última generación con técnicos muy formados y de alta confianza del gobernante para diseñar de 
manera continua escenarios, mapas de actores, análisis de viabilidad, análisis de problemas, saldo del intercambio de problemas y análisis de los cinturones de gobierno (35), entre otras técnicas y métodos que colaboren en la toma de decisiones. Con ello se busca acotar la improvisación, es decir, limitar la aplicación del "teorema del quinto oscilante" (i). No debemos confundir asesores especialistas con una unidad de procesamiento tecnopolítico. Los primeros tienen lógicas disciplinares, la segunda se estructura a partir de análisis de problemas. La concepción de la sala de situación en Carlos Matus, es muy superior al empobrecimiento conceptual que hicieron de ella la Organización Panamericana de la Salud y el Banco Mundial en el campo de la salud.

\section{Presupuesto por programas}

La técnica presupuestaria se aplica tradicionalmente como una variable de poder con la que se castiga o se premia. Su desarrollo conceptual está más cercano a las experiencias familiares de administración del dinero y a la vieja libreta del almacenero, que a las modernas técnicas presupuestarias como la del presupuesto por programas (72), que propone descentralizar el presupuesto a cada unidad de producción en función de un plan de acción, con definición de objetivos, actividades, tiempos, productos, responsables e indicadores. Se busca así eliminar la figura de un administrador todopoderoso sentado encima del presupuesto y jugando a no gastar porque "no se sabe qué puede pasar". En el presupuesto por programas, los actores que formulan el plan deben tener capacidades para definir sobre el dinero necesario para cada acción, lo cual no los desliga de las responsabilidades de rendición de cuentas sobre el mismo. También se debe reconocer que no pocas veces se lo utiliza como un eslogan, mientras se sigue con la vieja cultura presupuestaria de presupuesto histórico, solo que Ilamándola ahora presupuesto por programas.

\section{La comunicación}

Según Bourdieu, la maldición de las ciencias del hombre es la de ocuparse de un objeto que habla (42). El gobernante/gestor, en general, ignora esta dificultad $y$, por lo tanto, tiene serios problemas de comunicación hacia adentro y hacia afuera de la organización. El gobernante es normativo también en lo comunicacional, desconoce la complejidad del lenguaje y entonces lo aplica de una manera tan simple que empeora lo que pretendía mejorar. Tampoco conoce las propuestas que asocian al lenguaje con el trabajo y/o la organización (61-63). Para él, el lenguaje sirve para dar órdenes, pero ignora que la orden es imposible ya que en el momento último de la acción, la que decide es la libertad, no la orden (47). Lejos de esa concepción sartreana de la libertad, nuestro gobernante parece un pichón de Taylor, solo que cien años después.

El desafío que se le presenta al gobernante es el de poder establecer códigos comunicacionales que condicionen las anécdotas para problematizar y conceptualizar las situaciones que conforman el día a día de la vida institucional. Si esos códigos comunicacionales se establecen, se facilitará construir una cultura de conversaciones de alta calidad, donde decir sea sinónimo de hacer (6063). Así se podrá avanzar en fortalecer una narrativa de la organización (j) centrada en la tarea, que debería permitir que el grupo devenga operativo y la tarea pueda desplazar a la queja y al malestar en las conversaciones de los trabajadores (74). A su vez, esa narrativa fortalecerá la mística al interior de los grupos donde se cambiará la lógica desde un "aceptar" a un "creer". La determinación de la mística a las narraciones y de estas a las conversaciones es una construcción necesaria para una nueva institucionalidad, que le asigne a lo comunicacional un rol central. Es evidente que es mucho más fácil escribirlo que hacerlo.

El no trabajar el tema de la comunicación puede llevar al gobernante a quedar preso de un círculo pequeño que es el único que le brinda confianza y "le cuenta" cómo es la realidad. Es sabido que el gobernante valora los problemas y las oportunidades, en buena medida, por el peso de los canales de comunicación por los que accede a conocerlos. El riesgo es que se instale una lógica de comunicación en la que se priorice al mensajero sobre el mensaje, o que se lo tome como chivo emisario: "el mensaje es malo, maten al mensajero". Esta situación está muy lejos de lo que aconsejaba Confucio a Zilu ante la pregunta sobre cómo asistir al príncipe: "Dile la verdad, aunque esta lo ofenda" (75 p.128). 


\section{Las políticas para el personal}

Cuando no están ausentes, parecen diseñadas por Frederick Taylor y Henry Ford, ya que, en general, conciben al trabajador como un homo economicus, y piensan por lo tanto en él solo en términos de puja salarial. Sin embargo, los trabajadores constituyen el principal capital de la organización y su pertenencia al proyecto institucional no se define solo en términos salariales, sino en términos de identidades, narrativas y mística. Se desconoce que lo simbólico es central en el proceso de identificación con la organización y el proyecto político, y que para muchos de sus trabajadores el lenguaje es el principal instrumento de trabajo. Tanto desconocimiento lleva al gobernante o al gestor a pensar en que la mejor opción es tercerizar, ya que "a esta gente es imposible hacerla trabajar". La tercerización aparece como respuesta a la imposibilidad de construir un nosotros (nos-otros), no como identidad sustancial que antecede, sino como espacio al que se ingresa para construirlo (76)

\section{El proyecto de trabajo}

La tarea o el trabajo no siempre son el eje de la reflexión de los equipos; sin embargo, se verán imposibilitados de actuar si permanecen centrados en la queja y en el malestar. Las reuniones para reflexionar sobre el trabajo, en la visión tradicional del administrador, son inútiles porque imagina al trabajador como un trabajador manual, donde la comunicación se limita a escribir las indicaciones en un papel, de allí el remanido "pásemelo por escrito" de clara herencia taylorista. El tiempo que los trabajadores destinen a dialogar sobre el trabajo será una inversión que permitirá reflexionar sobre dimensiones simbólicas (representaciones, conversaciones, narrativas y mística), componentes centrales en la constitución de equipos e identidades.

\section{El nomadismo}

El gobernante y el gestor deben pensarse como nómades para poder intervenir de manera directa y sin intermediarios en la red de conversaciones que constituyen el territorio de su organización. El sedentarismo permite los entornos y los "diarios de Yrigoyen" (k). Es muy importante el acceso del dirigente a la realidad de manera directa, para evitar quedar encerrado en un sistema de comunicación de pocas personas que le dicen cómo es la realidad. Al caminar la organización marcará presencia y definirá encuentros (nuevos y programados), tendrá además la posibilidad de manejar el tiempo y decidir cuándo se va de esa reunión en un pasillo, o en una oficina que no es la suya. Ese nomadismo no puede circunscribirse a los límites de la organización, debe extenderse al territorio donde están los beneficiarios y/o demandantes de acciones, para establecer con ellos conversaciones directas, sin intermediarios ni mensajeros. Esto le permitirá conocer de primera mano cómo se está percibiendo su accionar y qué nuevas demandas y/o problemas han surgido. Por eso es que postulamos un modelo "todo terreno" y "anfibio" (77) para el gobernante y el gestor, ya que sus capacidades deberán alcanzar todos los espacios de la organización y del territorio. No puede gobernar desde el escritorio; es necesario resignar los modelos piramidales que construyeron a los gestores y trabajadores en los diversos procesos de socialización que atravesaron en sus diferentes etapas vitales (la familia, la escuela, la iglesia, el ejército, etc.) y apostar a construcciones de tipo rizomáticas (I) (79), si pretende que el proyecto supere su momento vital.

\section{Las reuniones de gabinete}

Estas reuniones, al igual que las de comisiones o comités dentro de una institución, no suelen tener mucha popularidad. ¿Por qué generan tan poca adhesión? Porque son desorganizadas, improductivas y repetitivas. En general, se caracterizan por no tener o no cumplir los horarios de inicio ni de finalización, por lo que la entrada y salida de participantes se hace de manera continua. Esa dinámica se potencia por las interrupciones que provocan los celulares que no dejan de sonar. Se pueden predecir comportamientos (se sabe lo que va a decir fulano o sultano ante tal situación) y muchas veces la reunión tiene más una función de catarsis que de espacio creativo. No hay agenda o, si la hay, no se la 
conoce con anticipación, nadie lleva registro de lo conversado, ni tampoco de los compromisos, no hay un coordinador $y$, si lo hay, no es rotativo. El uso de la palabra no es democrático, no está pautado en tiempo y no hay lista de oradores. Las anécdotas se suceden y se repiten sin ninguna conceptualización. Los temas rara vez son de interés de todos, lo que facilita diálogos aislados y/o superpuestos; no hay autoevaluación del proceso; se llevan años con el mismo ritual y parece imposible cambiarlo. ¿Qué hacer? Fijar horario de inicio y fin y, por supuesto, cumplirlos. Definir agenda y socializarla con anterioridad. Tratar solo temas de relevancia multilateral (de todos los participantes), todo aquel tema que no sea multilateral motivará otra reunión con la presencia únicamente de los interesados. Con esto se evitará la desconexión de los participantes por falta de interés y/o desconocimiento del tema tratado. Habrá una coordinación rotativa de la reunión. El inicio de la siguiente reunión comenzará con la lectura de los puntos abordados en el encuentro anterior y la rendición de cuentas de quienes hubieran tomado compromisos. Las reuniones de gabinete obedecen más a la cultura grupal que a las técnicas de gestión, pero podrían mejorar si se practicaran algunas de las propuestas mencionadas.

\section{Los tres cinturones de gobierno}

Hay tres cinturones (balances) que Matus aconseja monitorear y nunca ajustar todos juntos (35). El balance de gestión política es el que sintetiza los resultados positivos y negativos que se logran en el ámbito específico, que da respuesta o no a las demandas políticas de los actores sociales y la población en general, en el que el recurso crítico es el poder. El balance macroeconómico es el que registra los resultados y las consecuencias políticas del manejo macroeconómico y los resultados económicos alcanzados, cuyo recurso escaso y crítico son los medios económicos. Y el balance de intercambio de problemas específicos, que es el saldo de efectos políticos que genera el enfrentamiento de esos problemas que la población valora y donde los recursos escasos y críticos son los económicos, el poder político y principalmente las capacidades de gestión. Los dos criterios centrales en el análisis de estos balances son los de eficacia técnica y eficacia política (35). Si el monitoreo de los tres cinturones da un balance positivo será un aliciente para el gobernante, si fuera negativo deberá establecer nuevas estrategias y acciones en el corto plazo.

\section{La construcción de equipos}

En el devenir de gobernar, el dirigente estará sometido a una fuerte tensión que marcará límites a su modo de vida. La falta de equipo, que creyó que podía sustituir combinando expertos de distintas profesiones, no demorará en demostrarle su error. Si al momento de gobernar/gestionar está solo, es porque no ha podido construir equipos. El número de sus integrantes y los perfiles estarán definidos por las propias características de la organización, pero es conveniente pensar en equipos numerosos y heterogéneos de manera de poder diversificar las lógicas y las miradas, para así dar cuenta de la multiplicidad de situaciones que se enfrentan $y$, a la vez, asegurar la continuidad del proyecto en el tiempo a través de los integrantes más jóvenes. Habrá que ocupar diferentes puestos, tener jugadores con distintas características, conscientes de que habrá jugadas en las que algunos tendrán un rol más destacado que otros, por lo que los narcisismos deberían resignarse en función del bien común. Como todo proceso relacional y grupal, no está exento de la posibilidad del conflicto. Se debe volver a Sartre para recordar que "...el grupo se hace para hacer y se deshace haciendo" (33 p.502). La construcción de los equipos Ileva muchos años, y sus productos se explicitan cuando se ve a jugadores que "juegan de memoria", donde no es necesario que hablen para una acción, ya que una mirada basta. No hay acá tampoco recetas; quizá podemos encontrar algunas pistas en los juegos colectivos. Lo que seguro no debemos confundir es equipo con grupo de amigos y/o parientes.

Al listado de métodos y técnicas ya enunciados pueden sumarse otros, tales como: análisis de problemas, análisis estratégicos, técnicas de escenarios, mapas de actores, técnicas de simulación, evaluación y monitoreo de la gestión pública y técnicas de juego, por citar algunos de los más relevantes (38). Todos ellos 
deberían estar al servicio de lo político a través de la política y las capacidades de gobierno. La autonomía de las teorías, métodos y técnicas de gobierno implicaría caer en propuestas tecnocráticas y nada está más lejos de nuestra intención que favorecer dicha lógica. Pero también reconocemos que su uso estará condicionado por los intereses de los actores/agentes, por lo que podremos encontrar diferencias en su aplicación que responderán no solo al conflicto de interés sino también al conflicto cognitivo.

\section{LAS CAPACIDADES DE GOBIERNO INSTITUCIONALES}

¿Cuáles son los componentes de esas capacidades de gobierno institucionales? El capital que la organización pone a disposición del gobernante: capacidades institucionales, capacitación y motivación del personal, situación económica y financiera de la organización, estado edilicio, y valores culturales (mística, narrativa y calidad de las conversaciones), entre los más importantes.

Los avances democráticos de las últimas décadas en la región no siempre han significado una nueva institucionalidad. La sensación de imposibilidad de cambiar el aparato burocrático está más que generalizada entre quienes han pasado por alguna experiencia de gestión. Oscar Oszlak afirma: "La burocracia estatal, viuda administrativa de sucesivos gobiernos y regímenes políticos, acaba convirtiéndose en un inmenso cementerio de proyectos políticos" (80).

Del mismo modo que para fortalecer las capacidades de gobierno podemos pensar en "escuelas de gobierno" (10), para las capacidades institucionales se requiere una nueva institucionalidad, que no es posible si no se realiza una profunda reforma del Estado. Con esta afirmación nos diferenciamos de las propuestas de reformas de segunda generación, planteadas por los organismos internacionales siguiendo los lineamientos del Consenso de Washington (17), denominación con la que pretendían establecer una "secuencia inevitable, según la cual la lógica del proceso de transformación estatal debe ajustarse a un curso lineal y predeterminado" (19 p.1), o por autores que enmarcaron sus propuestas en dicha lógica y pretendían a través de un conjunto de procesos e instrumentos de gestión -visión tecnocrática de la reforma $(18,81)$ - ocultar sus objetivos políticos (82).

Oscar Oszlak describe que la historia del siglo XX tiene innumerables experiencias de intentos de reformas estatales, conocidas en su mayoría como reformas administrativas, relacionadas a distintos momentos históricos y diferentes estrategias de desarrollo, donde cada reforma le asignó un rol al Estado y a los gobiernos (19). No podemos decir que estas hayan sido útiles para construir capacidades institucionales $y$ entonces nos preguntamos: ¿por qué han fracasado sistemáticamente las reformas del Estado en América Latina?

El tema del Estado no es un problema de tamaño, es un problema de concepción. Nosotros estamos a favor de una "reforma de Estado" pero que rompa, en tanto formulación, con la propuesta que preconiza un Estado chico y eficiente. La discusión de la reforma del Estado exige la participación de los trabajadores y los conjuntos sociales que utilizan dichas instituciones. La reforma pensada desde una lógica externa (7), es decir, una ley que atraviese las instituciones y defina de manera normativa los contenidos de la reforma, está condenada al fracaso, independientemente de quienes la lleven adelante $(7,83)$, como lo demuestran los procesos de reforma del Estado que se han encarado en América Latina en las últimas décadas con nulos o pobres resultados.

Se debe explorar la reforma desde una lógica interna $(7,84)$, es decir, dando lugar a que los ciudadanos y los trabajadores puedan pensar y discutir el significado y el sentido social de esas organizaciones y de esos trabajos; es decir, los porqué y para qué de la institución. Eso puede desencadenar el proceso de cambio y resignificación (7); pero, para ello, es necesario meterse con las estructuras mentales de esos trabajadores y su relación con el trabajo, buscando crear otra cultura organizacional. Será necesario crear una nueva masa crítica que permita poner a estas organizaciones al servicio de las necesidades reales de la población y bajo su control. Esta propuesta se basa en reconocer 
que las estructuras mentales y la cultura organizacional tienen influencia decisiva sobre las prácticas de trabajo y las formas organizativas; esto explica por qué las modificaciones de los organigramas no producen cambios en las organizaciones (10). En síntesis, la reforma interna está pensada para ser realizada con los ciudadanos y con los trabajadores de cada institución; en cambio, la reforma externa, al no pensar en ellos como agentes de cambio, termina siendo contra los trabajadores.

Mario Testa señala que los sectores dominantes utilizan el poder que tienen para crear formas organizativas; en cambio, los sectores dominados solo disponen del poder de las organizaciones que consiguen crear, por lo que no tienen otro recurso que la conciencia en torno de los problemas que enfrentan, junto con el poder político (transitorio) que se deriva de ello (50).

Hay que pensar una nueva institucionalidad más allá de los edificios y los organigramas estructurados por lógicas piramidales. Se deben diseñar dispositivos de base territorial que produzcan vínculos directos y personalizados entre trabajadores y usuarios. ¿Podremos pasar de aceptar resignadamente a las instituciones, a creer e identificarnos con ellas?

\section{REFLEXIONES FINALES}

En este texto trabajamos básicamente con el "último" Matus, el que se dedicó a pensar y polemizar sobre las capacidades institucionales y personales para gobernar. El lector podría preguntarse si esa experiencia surgida en lo que se dio en llamar "el socialismo por la vía democrática" no es demasiado lejana, y si todos los hechos históricos vividos en las últimas décadas, y que sacudieron al mundo, no la hacen aún más distante y, por lo tanto, esa obra esté fuera de época. La pregunta sería lógica, pero no usaremos la obra de Matus para la respuesta. Tampoco los relatos de "Pepe" Mujica (27), Luis Ignacio Lula Da Silva (28) o Dilma Rouseff (29), sino que para responder recurriremos a Álvaro García Linera, actual vicepresidente de Bolivia $(85,86)$.

En el VI Foro de Filosofía de Venezuela, en la conferencia inaugural, Álvaro García
Linera, docente universitario de larga militancia, señala que una vez que uno se hace cargo del gobierno, aparecen otras tareas que él no encuentra en las obras clásicas del marxismo con las cuales se formó. Así, reflexionando sobre la complejidad de gobernar y lo que él Ilama las tensiones creativas que se enfrentan, en cierto momento de la conferencia se dirige a su viejo profesor, el filósofo argentino exiliado en México Enrique Dussel, y le señala: "eso yo no lo veía cuando era profesor -compañero Enrique Dussel- cuando estoy en el gobierno me doy cuenta de eso, no se puede ver desde afuera a veces" (86). Luego, al retomar la idea de cómo enfrentar esos dilemas y construir hegemonía (en tanto liderazgo intelectual y moral) afirma: "no hay salida, no hay una respuesta, no la encuentro compañero profesor, no la encuentro, y creo que otra vez la clave es cabalgar esas contradicciones" (86). ¿A qué se refiere con esas afirmaciones? A la complejidad de gobernar, a las tensiones que se "resuelven" de manera creativa y que limitan el "debe ser".

Su reflexión frente a las tensiones que se enfrentan en todo proceso de gobierno es que no hay "una salida", no hay respuestas a priori, hay que vivirlas, hay que aprender a moverse en un delicado equilibrio entre ambos polos de las contradicciones sabiendo de lo complejo y de la necesidad de una acción permanente, lo que no es siempre entendido por los que observan desde afuera:

\footnotetext{
Esto es lo que no entienden algunos intelectuales arrepentidos que sustituyen la realidad por divagaciones conceptuales, que nunca se mancharon en el fragor de las batallas reales de la plebe $y$ que ahora, ante las recientes e inevitables dificultades de esta nueva fase, abandonan el barco al que se adhirieron por moda para regresar al seno de la clase media de la que nunca se desprendieron realmente. (85 p.48)
}

Lo político tiene su propia esencia y diferentes soportes como la militancia, el territorio, la ideología, el carisma de sus dirigentes, los valores, la cultura, la historia, etc. En este texto nos abocamos a reflexionar sobre uno de esos soportes, las capacidades de gobierno, y lo hicimos convencidos de que es posible combinar 
ciencia con ideología para gobernar, como es posible también sumar voluntades, convicciones y capacidades tecnopolíticas para que el gobierno y la gestión colaboren en viabilizar el proyecto político y no se transformen en un obstáculo. Para ello es necesario construir una teoría para la práctica de gobernar/gestionar, construcción que debe partir de esa práctica para no caer en propuestas tecnocráticas propias de la razón instrumental. Esa construcción deberá reconocer que gobernar requiere de acciones creativas que obligan a utilizar la teoría como caja de herramientas (87) y a realizar apuestas cuya concreción dependerá de la fidelidad a las mismas. Esa construcción pone en tensión la lógica propia de los saberes disciplinarios que se construyen en profundidad (saben cada vez más, de menos cosas), con la lógica propia de lo que estamos planteando, que se construye en transversalidad (saber cada vez menos de más cosas), lógica que no es dominante en las universidades.

En situaciones de gobierno, lo político, en tanto ideología, debe operacionalizarse en políticas y estas requieren -entre otras cosas- de teorías, métodos y técnicas de gobierno para poder transformarse en acciones, en un juego muy complejo lleno de sorpresas e incertidumbres. Así todo, esas acciones deberían guardar relación con lo político de manera de poder conformar una circularidad virtuosa. No asumir la relevancia de las capacidades de gobierno personales e institucionales implica el riesgo de debilitar los alcances logrados en las últimas décadas en la mayoría de los países de América Latina.

\section{NOTAS FINALES}

a. Gobernar: "Gobernar es interferir en el desarroIlo del juego con la intención calculada de alcanzar un propósito" (10 p.406). Gestionar: "el arte de pensar, de decidir y de actuar; es el arte de hacer y acontecer, de obtener resultados. Resultados que pueden ser definidos, previstos, analizados y evaluados, pero que tienen que ser alcanzados a través de las personas en una interacción humana constante" (11 p.25).

b. Cuando hacemos referencia a gobernar no estamos apelando de manera exclusiva a la figura máxima de un país, ya que si bien los señalamientos pueden caberle o no, sí le caben a buena parte de sus equipos, que son quienes Ilevan adelante sus políticas, sus indicaciones o las respuestas a sus pedidos o el de los ciudadanos/as. En síntesis, no hablamos en un sentido unipersonalista sino en un claro sentido republicano, es decir, poderes e instituciones que tienen en una persona presidente/a, ministro/a, secretario/a, gobernador/a, intendente/a, etc., la representación y responsabilidad de gobernar/gestionar.

c. Una limitación del idioma español es que no tiene términos que diferencien "policy" que en este texto estaremos trabajando como políticas, de "politics" que referencia al arte y ciencias de gobierno.

d. Las reformas de segunda generación son las que surgen en el marco de las reformas del
Consenso de Washington y que plantean: privatización, descentralización, tercerización y reformas laborales, entre sus principales acciones. A diferencia de otras reformas ocurridas en el pasado en América Latina, estas reformas no se proponen introducir cambios sino retirar áreas del ámbito estatal. Cuentan con documentos de referencia como Más allá del consenso de Washington: La hora de la reforma institucional (17) y La reinvención del gobierno: La influencia del espíritu empresarial en el sector público (18). Una de las críticas puede encontrarse, por ejemplo, en "De menor a mejor: El desafío de la segunda reforma del Estado" (19).

e. Los tres términos son comunes en la jerga de la política partidaria y remiten a acciones que carecen de transparencia. La "rosca" o "rosquear" remite a acciones de negociación realizadas en función de relaciones que tienen como objetivo el intercambio de favores y/o alcanzar ciertas posiciones. El "verso" o "versear" se refiere a enunciaciones "políticamente correctas" para la situación pero sin que el que las emita las considere necesariamente verdaderas y/o tenga el propósito de ejecutar y alcanzar las acciones enunciadas. El "poroteo" o "porotear" remite a un intercambio de cargos, posiciones u objetos que son parte de una transacción secreta en función de construir adherencia al proyecto.

f. Sísifo, según la mitología griega, hizo enfadar a los dioses por su extraordinaria astucia y, como castigo, fue condenado a perder la vista y empujar perpetuamente una piedra gigante, montaña 
arriba, hasta la cima, para que al llegar volviese a caer rodando hasta el lugar de donde había salido y así infinitamente.

g. Usaremos en el texto de manera indistinta cada concepto, aunque algunos de los autores citados sean enfáticos en el uso de agentes y no de actores (42) y viceversa (24).

h. Cuando leí esto en la obra de Carlos Matus, no pude dejar de recordar a mi madre, quien dedicada al trabajo doméstico y con solo la escuela primaria completa repetía: "necesito un día de 48 horas" y "no sé en qué idioma hablo", lo cual demuestra que los problemas de comunicación y tiempo no son patrimonio exclusivo de la gestión ni del gobierno, pero pareciera que el sentido común da cuenta de ellos antes que la ciencia.

i. Forma utilizada para la toma de decisiones que consiste en extender el brazo de manera perpendicular al cuerpo, separar los dedos de la mano y rotarla reiteradamente en su propio eje a 90 grados para afirmar en un tono pensativo: "y... más o menos ponele que son..."

j. Utilizaremos el concepto de narrativa para describir formas de narrar que realizan una mediación entre el mundo interno de los pensamientos y sentimientos y el mundo externo de las acciones observables, y que dan como resultado la consolidación, variación o transformación en el sentido y el significado de una sucesión de hechos al interior de esa u otra organización, de los diferentes grupos y/o los distintos trabajadores que la componen (73).

k. Durante el segundo mandato del ex presidente radical Hipólito Yrigoyen (1928-1930), se habría creado un diario ficticio -se imprimía un solo ejemplar- para que el presidente pudiera leer aquellas "buenas noticias" redactadas por su entorno. Desde luego, esa información no se correspondía con la realidad.

I. Tomamos la definición de rizoma del libro Cartografías del deseo: "Ios diagramas arborescentes proceden por jerarquías sucesivas, a partir de un punto central, en donde cada elemento local vuelva a ese punto de origen. Al contrario, los sistemas en rizomas o en enrejados abiertos pueden derivar al infinito, establecer conexiones transversales sin necesidad de centrarlos o cerrarlos. El término rizoma ha sido obtenido de la botánica, donde define los sistemas de tallos subterráneos, de plantas vivaces que emiten botones y raíces adventicias en su parte inferior (ejemplo: rizoma del lirio)" (78 p.207-208).

\section{REFERENCIAS BIBLIOGRÁFICAS}

1. Brittan S. The economic contradictions of democracy. British Journal of Political Science. 1975;5(1):129-159.

2. Nordhaus W. The political business cycle. Review of Economics Studies. 1975;42:169-190.

3. Habermas J. Problemas de legitimación en el capitalismo tardío. Buenos Aires: Amorrortu; 1975.

4. Offe C. Contradiction of the Welfare State. Cambridge: IMS Press; 1984.

5. Offe C. Disorganized capitalism. Cambridge: Polity Press; 1985.

6. Giddens A. Sociología. Madrid: Alianza Editorial; 1993

7. Matus C. El líder sin Estado Mayor: la oficina del gobernante. La Paz: Fondo Editorial Altadir; 1997.
8. Mouffe C. En torno a lo político. Buenos Aires: Fondo de Cultura Económica; 2011.

9. Laclau E. La deriva populista y la centroizquierda latinoamericana. Nueva Sociedad. 2006;(205):56-61.

10. Matus C. Teoría del juego social. Buenos Aires: Ediciones de la UNLa, Universidad Nacional de Lanús; 2007.

11. Motta PR. La ciencia y el arte de ser dirigente. Bogotá: Ediciones Uniandes; 1993.

12. Tolstoi L. War and peace. New York: WW Norton; 1966.

13. Testa M. Decidir en Salud, ¿Quién?, ¿cómo? y ¿por qué? Salud Colectiva. 2007;3(3):247-257.

14. Giddens A. La constitución de la sociedad: Bases para la teoría de la estructuración. Buenos Aires: Amorrortu; 2006.

15. Bourdieu P. El sentido práctico. Salamanca: Siglo XXI Editores; 2008. 
16. Weber M. El político y el científico. México DF: Colofón; 2010.

17. Burki SJ, Perry GE. Más allá del Consenso de Washington: La hora de la reforma institucional. Washington DC: Banco Mundial; 1998.

18. Osborne D, Gaebler T. La reinvención del gobierno: La influencia del espíritu empresarial en el sector público. Buenos Aires: Paidós; 1994.

19. Oszlak O. De menor a mejor: El desafío de la segunda reforma del Estado. Nueva Sociedad. 1999;(160):81-100.

20. Maquiavelo N. El príncipe. Buenos Aires: Alianza Editorial; 1992.

21. Palacio-Rada J. Las ideas políticas en la Educación del príncipe cristiano de Erasmo de Rotterdam. Revista de Filosofía. 2010;(66):25-49.

22. Troyat H. Catalina la Grande. Buenos Aires: Vergara; 2005.

23. Feijoó JV. Mercado, socialismo y libertad: Economía y política en Rousseau. Santiago: LOM Ediciones; 2003.

24. Matus C. Adiós, señor presidente. Buenos Aires: Ediciones de la UNLa, Universidad Nacional de Lanús; 2007.

25. Obituary: Archbishop Paul Marcinkus. BBC News [Internet]. 21 feb 2006 [citado 26 dic 2011]. Disponible en: http://news.bbc.co.uk/2/hi/europe/4737372.stm.

26. Mazarin J. Brevário dos políticos. 7a ed. São Paulo: Editora 34; 2007.

27. Palabra de Mujica. Diario Crítico [Internet]. 3 mar 2010 [citado 12 ene 2012]. Disponible en: http://www.diariocritico.com/general/197032.

28. Da Silva LI. Discurso do Presidente da República, Luiz Inácio Lula da Silva, durante a cerimônia de comemoração dos 10 anos do Fórum Social Mundial Porto Alegre, 26 de janeiro de 2010 [Internet]. Presidência da República: 26 jan 2010 [citado 26 dic 2011]. Disponible en: http://www.biblioteca.presidencia.gov.br/ex-presidentes/luiz-inacio-lula-dasilva/discursos/2o-mandato/2010/1o-semestre/26-01-2010-discurso-do-presidente-da-republica-luiz-inacio-lula-da-silva-durante-a-cerimonia-de-comemoracao-dos-10-anos-do-forumsocial-mundial/at_download/file.
29. Rousseff: "Todos los días hay que escalar un Everest" [Internet]. Buenos Aires: InfoNews; 1 mar 2011 [citado 29 dic 2011]. Disponible en: http://www.infonews.com/nota.php?id = 128296 \&bienvenido $=1$.

30. Fabiana Ríos, otra gobernadora que se siente marginada [Internet]. Perfil.com; 17 sep 2008 [citado 29 dic 2011]. Disponible en: http://www.perfil.com/contenidos/2008/09/17/n oticia_0016.html.

31. Huertas F. Planificar para gobernar: El método PES. Entrevista a Carlos Matus. Buenos Aires: Universidad Nacional de La Matanza; 2006.

32. Matus C. Estrategia y plan. 9a ed. México DF: Siglo XXI Editores; 1989.

33. Feinmann JP. La filosofía y el barro de la historia. Buenos Aires: Planeta; 2008.

34. Panzeri D. Fútbol: dinámica de lo impensado. Buenos Aires: Paidós; 1967.

35. Matus C. Los 3 cinturones del gobierno: gestión, organización y reforma. Caracas: Fondo Editorial Altadir; 1997. p. 5-53.

36. Varsavsky O. Ciencia, política y cientificismo. Buenos Aires: Centro Editor de América Latina; 1974.

37. Matus C. Las Ciencias y la Política. Salud Colectiva. 2007;3(1):81-91.

38. Matus C. Política, planificación y gobierno. Caracas: Fundación Altadir; 1992.

39. Cohen WA. The art of the strategist. New York: Amacom; 2004.

40. Flores F. Inventando la empresa del siglo XXI. Santiago de Chile: Dolmen Ediciones; 1989.

41. Ackoff RL. Cápsulas de Ackoff: Administración en pequeñas dosis. México DF: Limusa; 1997.

42. Bourdieu P, Wacquant I. Una invitación a la sociología reflexiva. 2a ed. Buenos Aires: Siglo XXI Editores; 2008.

43. Tovillas P. Bourdieu: una introducción. Buenos Aires: Quadrata; 2010.

44. Spinelli H, Testa M. Del diagrama de Venn al Nudo Borromeo: Recorrido de la Planificación en América Latina. Salud Colectiva. 2005;1(3):323335. 
45. Spinelli $H$. Las dimensiones del campo de la salud en Argentina. Salud Colectiva [Internet]. 2010 [citado 29 dic 2011];6(3):275-293. Disponible en: http://www.scielo.org.ar/pdf/sc/v6n3/v6n3a04.pdf.

46. Morin E. La noción de sujeto. En: Schnitman D. Nuevos paradigmas, cultura y subjetividad. Buenos Aires: Paidós; 1994. p. 67-86.

47. Sartre JP. Crítica de la razón dialéctica. Buenos Aires: Losada; 1963.

48. Mintzberg H. La burocracia profesional. En: Diseño de organizaciones eficientes. Buenos Aires: El Ateneo; 2001. p. 159-179.

49. Mintzberg H. Rise and fall of strategic planning. New York: Free Press; 1994.

50. Testa M. Pensamiento estratégico y lógica de programación (el caso de salud). 2a ed. Buenos Aires: Lugar Editorial; 1995.

51. Castro E. El vocabulario de Michel Foucault: Un recorrido alfabético por sus temas, conceptos y autores. Bernal: Universidad Nacional de Quilmes; 2004.

52. Foucault M. Seguridad, territorio, población: Curso en el Collège de France, 1977-1978. Buenos Aires: Fondo de Cultura Económica; 2006.

53. Foucault M. El gobierno de sí y de los otros: curso en el Collège de France, 1982-1983. Buenos Aires: Fondo de Cultura Económica; 2010

54. Crainer S. Os revolucionários da administração: Um guia indispensável dos pensadores e suas idéas que criaram e revolucionaram a administração e o mundo dos negócios. São Paulo: Negócio Editora; 1999.

55. Loureau R. El análisis institucional. Buenos Aires: Amorrortu; 1975.

56. Bachelard G. O novo espíritu científico. En: A filosofia do não; O novo espíritu científico; A poétiva de espaço. São Paulo: Abril Cultura; 1978.

57. Matus C. Chimpancé, Machiavello y Gandhi: Estrategias políticas. Caracas: Fondo Editorial Altadir; 1995.

58. Shannon CE, Waever W. The mathematical theory of communication. Illinois: University of Illinois Press; 1998.

59. Wittgenstein L. Investigaciones filosóficas. Buenos Aires: Paidós; 2006.
60. Austin JL. Cómo hacer cosas con palabras: palabras y acciones. Buenos Aires: Paidós; 2006.

61. Searle JR. Actos de habla: ensayo de filosofía del lenguaje. Madrid: Ediciones Cátedra; 1990.

62. Bourdieu P. Cosas dichas. Barcelona: Gedisa; 1987.

63. Flores F. Entrevista. En: Creando organizaciones para el futuro. Santiago: Granica; 1997.

64. Echeverría R. Ontología del lenguaje. Buenos Aires: Granica, JC Saez; 2005.

65. Shotter J. Realidades conversacionales: La construcción de la vida a través del lenguaje. Buenos Aires: Amorrortu; 2001.

66. Mintzberg H. La adhocracia. En: Diseño de organizaciones eficientes. Buenos Aires: El Ateneo; 2001. p. 299-325.

67. Alazraqui M, Mota E, Spinelli H. Sistemas de información en salud: de sistemas cerrados a la ciudadanía social: Un desafío en la reducción de desigualdades en la gestión local. Cadernos de Saúde Pública. 2006;22(12):2693-2702.

68. Spinelli H. Condiciones de salud y desigualdades sociales: historias de iguales, desiguales y distintos. En: Minayo MCS, Coimbra Jr CEA, organizadores. Críticas e atuantes: Ciências sociais e humanas em saúde na América Latina. Rio de Janeiro: Fiocruz, 2005.

69. Guerrero O. La administración pública a través de las ciencias sociales. México DF: Fondo de Cultura Económica; 2010.

70. Crozier M. La transición del paradigma burocrático a una cultura de gestión pública. Revista del CLAD Reforma y Democracia [Internet]. 1997;(7) [citado 12 feb 2012]. Disponible en: http://www.clad.org/portal/publicaciones-delclad/revista-clad-reforma-democracia/articulos/007-enero-1997/0029601.pdf.

71. Weber M. Economía y sociedad: esbozo de sociología comprensiva. Buenos Aires: Fondo de Cultura Económica; 1992.

72. Matus C, Makon M, Arrieche V. Las bases teóricas del Presupuesto por Programas. Caracas: AVPP; 1977.

73. Mattingly C, Garro LC. Narratives and the cultural construction of illness and healing. Berkeley: University of California Press; 2000. 
74. Pichon-Rivière E. Obras Completas. Buenos Aires: Nueva Visión; 1997.

75. Confucio. Analectas: versión y notas de Simon Leys. 3ra ed. Madrid: Editorial EDAF; 2006. p. 128. (Colección Arca de Sabiduría).

76. Lewkowicz I. Pensar sin Estado: La subjetividad en la era de la fluidez. Buenos Aires: Paidós; 2008.

77. Almeida-Filho N, Silva-Paim J. La crisis de la salud pública y el movimiento de la salud colectiva en Latinoamérica. Cuadernos Médico Sociales. 1999;(75):5-30.

78. Kaminsky G, compilador. Guattari: Cartografías del deseo. Buenos Aires: La Marca; 1995.

79. Deleuze G, Guattari F. Mil mesetas: capitalismo y esquizofrenia. Valencia: Pre-textos; 1988.

80. Oszlak O. Oscar Oszlak [Internet]. Buenos Aires: CEDES [citado 10 ene 2012]. Disponible en: http://www.oscaroszlak.org.ar/index.php

81. Rodríguez-Larreta H, Quintana M. Domando al elefante blanco: Pasos para construir un Estado que funcione. Buenos Aires: Grupo Sophia, Temas Grupo Editorial; 1998.

82. Vilas CM. El síndrome de Pantaleón: Política y administración en la reforma del Estado y la gestión de gobierno. Buenos Aires: AAEAP; 2004.
83. Oszlak O. Quemar las naves (o como lograr reformas estatales irreversibles) [Internet] IV Congreso Internacional del CLAD sobre la Reforma del Estado y de la Administración Pública. México DF, 19-22 oct 1999 [citado 12 ene 2012]. Disponible en: http://www.oscaroszlak.org.ar/images/articulos-espanol/Quemar \% 20las\% 20naves.pdf.

84. Spinelli H. Além da quantidade e do objetivo: a avaliação como parte das micropráticas de trabalho. En: Onocko Campos R, Pereira Furtado J, Passos E, Benevides R, organizadores. Pesquisa avaliativa em saúde mental: Desenho participativo e efeitos da narratividade. São Paulo: Hucitec; 2008.

85. García-Linera A. Las tensiones creativas de la revolución: La quinta fase del proceso de cambio. La Paz: Vicepresidencia del Estado; 2011.

86. García-Linera A. Estado, revolución y construcción de hegemonía. VI Foro Internacional de Filosofía, Venezuela [Video en Internet]. 28 nov 2011 [citado 20 feb 2012]. Disponible en: http://www.youtube.com/watch?v=jkSRvfyfZp4.

87. Deleuze G. Foucault. Buenos Aires: Paidós; 1986.

\section{FORMA DE CITAR}

Spinelli H. El proyecto político y las capacidades de gobierno. Salud Colectiva. 2012;8(2):107-130.

Recibido el 20 de enero de 2012

Versión final presentada el 15 de mayo de 2012

Aprobado el 20 de junio de 2012 